\title{
CONVERGÊNCIAS E DIVERGÊNCIAS NOS DISCURSOS E NAS PRÁTICAS DE CONSUMO DOS PROFESSORES
}

Hérica Maria Saraiva Melo ${ }^{1}$ Denis Barros de Carvalho²

Resumo: Este artigo analisou convergências e divergências entre o discurso e a prática de consumo. A pesquisa utilizou entrevistas em profundidade com professores de uma escola técnica vinculada à Universidade Federal do Piauí. A partir da análise qualitativa de conteúdo surgiram aspectos da racionalidade econômica e ecológica. Os resultados demonstraram que a prática de consumo nem sempre é coerente com o discurso ambientalmente responsável, pela existência de elementos motivacionais (falta de interesse, comodidade) e contextuais (restrições de tempo, cultura, aspectos financeiros).

Palavras-chave: Práticas de Consumo; Discursos; Professores. 


\section{Introdução}

Atualmente, as práticas de consumo fazem o elo entre o indivíduo e o meio social (COSTA; TEODÓSIO, 2011) e são reconhecidas como cotidianas e executadas nas necessidades ilimitadas dos consumidores (BARBOSA, 2010). Cabe destacar que $O$ ato de comprar não se relaciona apenas com a subjetividade, além de raramente ser dirigido pela individualidade do consumidor que pratica a compra (WARDE, 2005). Dessa forma, a compra não é praticada de forma isolada, como pressupõe a abordagem da economia neoclássica.

Evidencia-se que as práticas de consumo precisam incorporar valores e compromissos éticos, pois o indivíduo, através da abordagem da ética da responsabilidade, é capaz de restringir a capacidade humana de agir como destruidor da autoafirmação do ser na existência da vida e da natureza para, a partir de então, promover um desenvolvimento sustentável. Faz-se necessário repensar uma nova ética que deverá romper os princípios básicos do utilitarismo e do consumismo, devendo ser pautada em princípios que levem em consideração uma relação do homem com a natureza mais afetiva (JONAS, 2006).

Para uma melhor compreensão de tais práticas, aborda-se a dimensão do "Cuidado Ambiental". O termo diz respeito aos comportamentos de proteção ao ambiente e tem sido empregado no contexto de atividades como educação ambiental, para se referir à postura ética e prática a ser adotada e mantida em relação à natureza, ao ambiente, à espaçonave Terra (BOFF, 2013). Nesse sentido, as práticas de consumo referenciadas pela ética da responsabilidade e pelo cuidado ambiental apontam para o que seria um interesse público e coletivo, convocando o consumidor a adotar novos comportamentos como prática de cidadania. Ao perceber o significado e as consequências de suas ações no meio ambiente e em outros grupos sociais, os nexos de fazeres e discursos das práticas de consumo podem representar um aumento dos sentimentos de cidadania e pertencimento a uma "comunidade imaginária" que ajuda a tornar estas práticas mais úteis e significativas (PORTILHO, 2008; 2010).

Trata-se de um processo que apresenta estreita relação com a ambientalização da vida cotidiana, percebida com mais intensidade a partir dos anos 1990. Ambos os processos tratam da tentativa de dar concretude à adesão dos agentes consumidores a valores em prol de melhorias sociais e ambientais, materializando-os e tornando-os públicos (PORTILHO, 2010; STOLLE; HOOGHE; MICHELETTI, 2005). Na interface entre consumo e sustentabilidade, ações políticas podem ser interpretadas como parte dos processos de ambientalização e politização do consumo e da vida privada e cotidiana.

Nessa perspectiva, é preciso que os consumidores percebam as consequências de suas escolhas e passem a adotar hábitos de consumo menos prejudiciais (PEIXOTO; PEREIRA, 2013). Entretanto, constata-se a

revista brasileira educação ambiental 
relação sempre dicotômica do consumidor entre preservar o meio ambiente e/ou atingir seus interesses pessoais. A partir do exposto, pretendeu-se responder à seguinte questão: Como os professores percebem suas práticas de consumo? A hipótese do estudo é que, de um modo geral, as pessoas ainda não têm incorporado comportamentos em prol do meio ambiente em suas práticas cotidianas, embora afirmem que têm a intenção de agir de forma ambientalmente consciente (BECK, 2010). Desse modo, as atitudes refletemse nos comportamentos e estão embasadas na orientação de valores relacionados a explorar os recursos naturais ou mantê-los (THOMPSON; BARTON, 1994). Com isso, o objetivo desta pesquisa foi caracterizar as práticas de consumo dos professores.

\section{Metodologia}

A pesquisa desenvolveu-se no Colégio Técnico de Teresina (CTT), vinculado à Universidade Federal do Piauí (UFPI), que oferta ensino básico, técnico e tecnológico. Para investigar as práticas de consumo dos professores do CTT, empregou-se a metodologia qualitativa, de caráter exploratório, por ser cada vez mais frequente nas ciências humanas, permitindo ao investigador aumentar sua experiência em torno do problema, buscando seus antecedentes e um maior conhecimento (GIL, 2006). A amostra caracterizou-se como sendo não probabilística intencional, caracterizada pela seleção não aleatória.

Optou-se por trabalhar com professores, uma vez que além de serem consumidores são formadores de opiniões e exercem um papel estratégico na construção de uma consciência ambiental. Entende-se que os professores enquanto consumidores e formadores devem repensar suas posturas enquanto cidadãos e docentes. Assim, considera-se pertinente conhecer as práticas de consumo dos professores, porque estes têm um papel fundamental para a formação de cidadãos responsáveis, a quem caberá tomar decisões de forma a resolver os problemas ambientais (KNAPP, 2000).

O atual quadro docente do CTT é formado por 41 professores, entretanto 34 estão em exercício e atuam em três cursos técnicos de áreas distintas, a saber: Agropecuária (Modalidade concomitante com o Ensino Médio e subsequente), Enfermagem (subsequente) e Informática (subsequente). A fim de garantir a heterogeneidade intergrupal, selecionamos dezoito professores através de sorteio. O Quadro 1 apresenta o perfil dos professores entrevistados. 
Quadro 1: Perfil dos professores entrevistados.

\begin{tabular}{|c|c|c|c|c|c|}
\hline \multirow[b]{2}{*}{$\begin{array}{c}\text { Professor } \\
\text { Entrevistado }\end{array}$} & \multicolumn{5}{|c|}{ Grupo 1 (Ensino Médio) } \\
\hline & Gênero & $\begin{array}{l}\text { Faixa } \\
\text { etária }\end{array}$ & $\begin{array}{c}\text { Nível de } \\
\text { escolaridade }\end{array}$ & Área de Formação & $\begin{array}{l}\text { Tempo de } \\
\text { docência }\end{array}$ \\
\hline P1 & Feminino & 40 a 49 & Especialização & Letras & 21 anos \\
\hline P2 & Masculino & 30 a 39 & Mestrado & Matemática & 8 anos \\
\hline P3 & Feminino & 50 a 59 & Especialização & Biologia & 20 anos \\
\hline P4 & Feminino & 50 a 59 & Doutorado & Biologia & 35 anos \\
\hline P5 & Feminino & 30 a 39 & Especialização & Educação Física & 2 anos \\
\hline P6 & Masculino & 30 a 39 & Mestrado & Inglês & 17 anos \\
\hline P7 & Feminino & 30 a 39 & Especialização & Espanhol & 9 anos \\
\hline P8 & Masculino & 30 a 39 & Mestrado & Física & 12 anos \\
\hline \multirow{2}{*}{$\begin{array}{l}\text { Professor } \\
\text { Entrevistado }\end{array}$} & \multicolumn{5}{|c|}{ Grupo 2 (Agropecuária) } \\
\hline & Gênero & $\begin{array}{l}\text { Faixa } \\
\text { etária }\end{array}$ & $\begin{array}{c}\text { Nível de } \\
\text { escolaridade }\end{array}$ & Formação & $\begin{array}{l}\text { Tempo de } \\
\text { docência }\end{array}$ \\
\hline P9 & Feminino & 40 a 49 & Doutorado & Engenharia Agronômica & 12 anos \\
\hline P10 & Feminino & 40 a 49 & Doutorado & Medicina Veterinária & 8 anos \\
\hline P11 & Feminino & 40 a 49 & Doutorado & Engenharia Agronômica & 5 anos \\
\hline P12 & Masculino & 40 a 49 & Doutorado & Medicina Veterinária & 6 anos \\
\hline \multirow{2}{*}{$\begin{array}{c}\text { Professor } \\
\text { Entrevistado }\end{array}$} & \multicolumn{5}{|c|}{ Grupo 3 (Agropecuária) } \\
\hline & Gênero & $\begin{array}{l}\text { Faixa } \\
\text { etária }\end{array}$ & $\begin{array}{c}\text { Nível de } \\
\text { escolaridade }\end{array}$ & Área de Formação & $\begin{array}{l}\text { Tempo de } \\
\text { docência }\end{array}$ \\
\hline P13 & Feminino & 18 a 29 & Especialização & Enfermagem & 1 ano \\
\hline P14 & Feminino & 50 a 59 & Mestrado & Enfermagem & 29 anos \\
\hline P15 & Feminino & 30 a 39 & Doutorado & Enfermagem & 12 anos \\
\hline P16 & Feminino & 50 a 59 & Mestrado & Enfermagem & 25 anos \\
\hline \multirow{2}{*}{$\begin{array}{c}\text { Professor } \\
\text { Entrevistado }\end{array}$} & \multicolumn{5}{|c|}{ Grupo 4 (Informática) } \\
\hline & Gênero & $\begin{array}{l}\text { Faixa } \\
\text { etária }\end{array}$ & $\begin{array}{c}\text { Nível de } \\
\text { escolaridade }\end{array}$ & Área de Formação & $\begin{array}{l}\text { Tempo de } \\
\text { docência }\end{array}$ \\
\hline P17 & Masculino & 30 a 39 & Mestrado & Computação & 7 anos \\
\hline P18 & Masculino & 18 a 29 & Especialização & Computação & 3 anos \\
\hline
\end{tabular}

Fonte: Autoria própria.

A participação dos docentes foi voluntária e obtivemos o Termo de Consentimento Livre e Esclarecido (TCLE), obedecendo à Resolução № 466/12. As entrevistas foram gravadas e duraram, em média, 30 minutos. $O$ método para o tratamento dos dados foi baseado na abordagem qualitativa através da Análise de Conteúdo (AC) orientada por Bardin (2009), que possibilitou a construção de categorias, bem como a geração das variáveis. A AC temática consiste em descobrir os núcleos de sentido que compõem uma comunicação cuja presença ou frequência signifiquem alguma coisa para o objetivo analítico visado (BARDIN, 2009; MINAYO, 2003).

\section{Resultados e discussão}

Para a compreensão do tema "Prática de consumo ambientalmente consciente" foram analisadas e caracterizadas as atitudes declaradas nas entrevistas, ou seja, o que os professores pensam, quais os interesses envolvidos e como dizem se comportar. A seguir, a Figura 1 apresenta as categorias e variáveis da temática analisada. 


\section{TEMA: Prática de consumo ambientalmente consciente}

Objetivo: Caracterizar a prática de consumo ambientalmente consciente dos professores

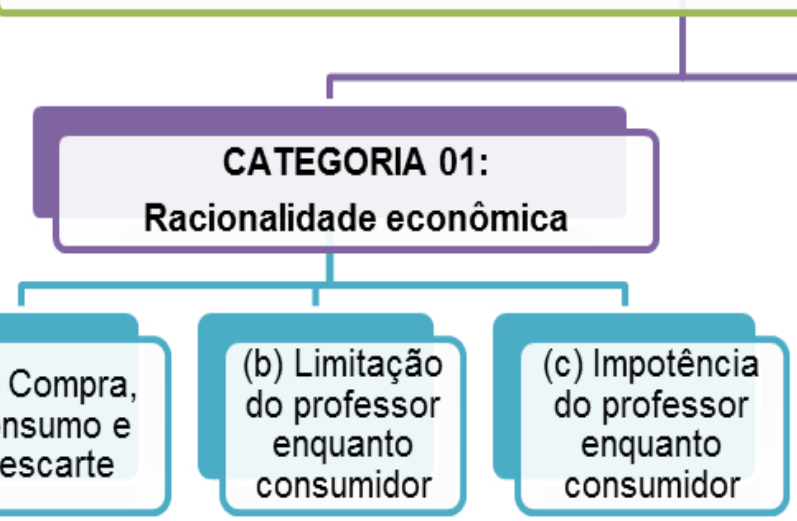

(a) Compra, consumo e descarte

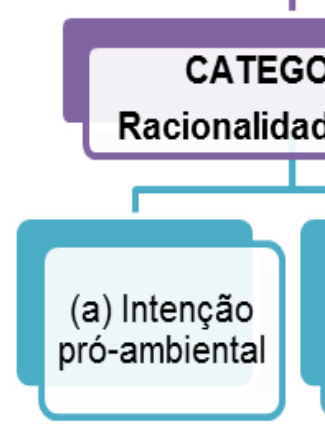

CATEGORIA 02:

Racionalidade ecológica

Figura 1: Categorias e variáveis do tema "prática de consumo ambientalmente consciente".

Fonte: Autoria própria.

A variável (a) Compra, consumo e descarte está relacionada com o processo de compra que, segundo o paradigma dominante na sociedade contemporânea, preza mais os aspectos econômicos do que os ecológicos. A decisão de compra do consumidor é um processo dividido em: (1) reconhecimento da necessidade; (2) busca da informação; (3) avaliação précompra de alternativas; (4) compra; (5) consumo; (6) avaliação pós-compra e (7) descarte (BLACKWELL; MINIARD; ENGEL, 2005).

Featherstone (1995) e Campbell (2006) afirmam que a compra e o consumo estão mais pautados em saciar vontades do que em satisfazer necessidades. Dessa forma "ele tá preocupado só com o bem estar dele, a qualidade de vida dele, mas não de um modo geral no meio em que ele tá inserido" (P3). Nesse sentido, a professora P1 afirma que "hoje em dia, você vive num mundo altamente consumista. Então, você consome pra agradar o seu eu, você consome pra satisfazer suas necessidades pessoais. [...] isso significa que os outros, que tudo aquilo que tá ao seu redor não existe". Para Schultz (2001), um dos problemas associados às questões ambientais é o atual nível e padrão de consumo das pessoas que vivem principalmente em países industrializados. "[...] quanto mais dinheiro, menos consciência tem uma sociedade e mais ela vai consumir" (P4). Dito em outras palavras, "quanto mais você tá ganhando, quanto mais você tem condição, mais você vai consumir e, muitas vezes, sem essa consciência ambiental" (P18).

O problema do consumo - hiperconsumo, consumerismo, crescimento (aumento das atividades econômicas), escala (extensão e Revbea, São Paulo, V. 11, № 1: 108-129, 2016. 
velocidade das atividades econômicas humanas e capacidade ecológica) e padrões de uso de recursos (quantidade e qualidade de produtos usados e seus significados) - é muito mais complexo (VAREY, 2010). Neste sentido, percebe-se que o futuro ainda parece ser uma realidade distante e os prejuízos ao meio ambiente não estão relacionados às suas atitudes individuais de compra. Nesta linha de pensamento, Lipovetsky (2007) argumenta que, na sociedade do hiperconsumo atual, compra-se o que dá prazer - e não mais apenas o que supre as necessidades fisiológicas. $\mathrm{O}$ ato de comprar está ligado à satisfação de necessidades e, mais do que isso, "como o consumo tem aumentado, esse aumento desenfreado... hoje em dia as pessoas não compram mais por necessidade, compram mais por uma questão de beleza ou de ego, também por uma questão de sanar algum problema que tenha com um prazer desses, vazio" (P17).

A avaliação pré-compra está ausente quando fica nítido que "consomese tudo o que está na moda porque está na moda" (P1), ou seja, não há uma reflexão acerca do impacto desse consumo para o meio ambiente. Complementando essa ideia, P11 afirma que "temos o hábito de querer tudo, de comprar porque tá na moda. Talvez você nem precise, mas você quer. Aí descarta aquilo que tá bom porque quer acompanhar o novo. Esse hábito de consumir, eu acho que o capitalismo é o que mais proporciona".

Conforme evidenciado na revisão de literatura, o consumo proporciona um aumento da qualidade de vida e o bem-estar almejado pelos seres humanos (LIPOVETSKY, 2007), mas está diretamente relacionado ao desenvolvimento econômico e, consequentemente, à degradação e à poluição que o progresso gera (VAREY, 2010). Assim, não é de se admirar que a conscientização acerca das consequências adversas provocadas pelos impactos do homem no meio ambiente entre em conflito com a desejada manutenção dos padrões de qualidade de vida proporcionados pelo consumo, conforme evidenciado pelas demonstrações egoístas de manutenção relacionadas aos próprios interesses.

Além disso, a cada escolha, seja para a aquisição de um bem durável ou para a compra de um produto para consumo diário, o consumidor se depara com uma infinidade de atributos a serem considerados ao tomar sua decisão e a variável ambiental entra em conflito com outras características como: preço, qualidade, marca, validade, durabilidade, status, entre tantos outros. Quando indagados acerca do que é mais importante na decisão de compras, é citado "aliar preço com qualidade, basicamente [...] porque pagar muito barato por uma coisa que não presta também não dá certo" (P2). "Eu presto muita atenção no preço, o preço é importante. [Também] coisas de qualidade. Eu não compro uma coisa de primeira, eu gosto de pesquisar, ver qualidade. Porque às vezes uma coisa é barata, mas não tem uma qualidade boa". Também complementando, há outro atributo que é observado, "por exemplo, no supermercado é a questão da validade e da conservação [do produto]" (P13).

revista brasileira educação ambiental 
Os comportamentos de compra estão muito associados a atributos ligados ao preço e à qualidade e esta característica representou quase uma unanimidade. Além do mais, é considerado também fundamental com relação ao produto, "se ele vai atender o objetivo do que eu quero, depende do que eu quero. Se for um carro, por exemplo, eu prezo muito com questão de consumo [de combustível] e de durabilidade. (...) eu sou pão duro pra botar combustível" (P17).

Porém, há uma consequência quando se considera como mais importante a qualidade do produto associada ao preço, por perceber que "isso leva lá pro problema ambiental. Porque você baixar preço, não necessariamente quer dizer que o seu custo de produção seja mais baixo. Geralmente é porque tem menos preocupação ambiental". Entretanto, "ao fazer compras, eu não me importo, isso é uma coisa que eu não observo" (P9).

Embora muitos autores argumentem que o diferencial do consumidor consciente é o de que considera, além do binômio qualidade-preço, também o meio ambiente (LAYRARGUES, 2000; PORTILHO, 2005); quando o atributo meio ambiente é citado, justifica-se a dificuldade de colocá-lo em prática, uma vez que "nosso país não tem essa cultura de cuidado na hora do consumo diário" (P1). É notório que ainda não está internalizado como um hábito, uma vez que "isso aí eu estou me acostumando, aprendendo" (P1).

Existe o conhecimento, mesmo que limitado, acerca do que poderia ser feito para não agredir o meio ambiente, quando "a gente observa onde é que é fabricado, como foi fabricado aquele produto, se tem alguma substância que você imagina que não seja agradável ao meio ambiente". Mas nada ligado a aspectos de consumir somente o necessário, ou seja, o produto que está dentro da embalagem. Também não há ainda a percepção da urgência de mudar os próprios comportamentos, pois "é uma coisa que a gente tá criando aos pouquinhos, é devagar, porque ninguém tem esse hábito" (P1). Ou seja, "não é uma preocupação muito grande ainda, mas eu observo de onde foi extraída aquela matéria prima. No supermercado eu também observo a questão dos transgênicos, como é que foi feito, o tipo de material utilizado, aquela matéria prima" (P3).

Percebe-se que, ao fazer compras, prioriza-se "a qualidade do produto, mas também como essa empresa tá tratando o meio ambiente" (P10). Entretanto, o consumidor ainda não está disposto a abrir mão de certas comodidades e produtos conhecidos, nem pretende abdicar de seus hábitos para satisfação de interesses imediatos. Isso faz com que se renda a atributos relacionados à "marca, beleza e status". Com relação à compra de carros, que representa um status social, "algumas empresas de fábrica de automóveis, elas se preocupam com a questão ambiental, mas aqui no Brasil ainda não tá, não é um determinante pra pessoa deixar de comprar um carro ou outro, porque o carro é mais ecologicamente adequado, né" (P17). 
Os professores demonstraram que não escolhem produtos ambientalmente corretos porque estes são considerados mais caros. Ceschim e Marchetti (2009) aplicaram uma pesquisa relacionada ao comportamento de compra de produtos orgânicos e concluíram que, no geral, estes são apontados como mais caros que as outras categorias de produto, ou seja, "alimento orgânico tem um preço diferenciado" (P9). Dito em outras palavras, "ainda é um alimento muito caro, que não chega com facilidade a nossa mesa. Então isso aí a gente não faz" (P1). Leva-se em consideração o baixo preço, "por exemplo, hortaliças, eu compro muito em horta comunitária que eu sei que produz orgânico" (P9). Em alguns casos, a compra de alimentos orgânicos surgiu por questões de saúde, como sendo prioridade, "porque eu tô fazendo tratamento de saúde e uma das coisas que a médica pediu foi isso. Então, agora eu tô comendo chia [...]É como remédio, inevitavelmente tem que comprar" (P17).

Nos resultados do estudo com jovens (AKATU, 2009) evidenciaram-se dois fatores motivadores para a aceitação de uma mudança de comportamento: (1) a percepção de que economizariam ao praticar atitudes pró-ambientais; e (2) a convicção de que estariam preservando o meio ambiente. Contudo, as evidências desta dissertação apontam para o fato que a variável ambiental não entra nos processos de decisão de compra. "Acho que a maior parte das pessoas nem pensa nisso. Mas seria importante olhar se esses objetos não são degradantes para o meio ambiente" (P8).

A atitude de "ao comprar o produto você observar que tipo de produto que você tá comprando, se aquele produto danificou ou não o meio ambiente" ou mesmo de comparar produtos antes da compra, de modo a colocar a variável ambiental como fator de decisão, também não foi um comportamento ativo e declarado pelos professores, uma vez que "essa parte aí eu estou aprendendo a fazer. [...] Isso aí é devagar, não tenho realmente muita prática com isso não $(\mathrm{P} 1)$. Isso demonstra que esta ideia parece inovadora e distante das preocupações cotidianas. Muito provavelmente, a utilização de energia solar ou eólica, "é inacessível, muito cara (P9) ou carro bicombustível, somente será uma realidade se estes novos produtos ambientalmente corretos apresentarem um preço mais baixo, já que o custo foi o fator mais citado na decisão de compra.

Estas citações são corroboradas por outros pesquisadores que também constataram que o preço ainda domina a decisão de consumo, reafirmando a racionalidade econômica em detrimento da ecológica, sendo que "às vezes, se acontece de eu encontrar uma promoção e eu ver que vale a pena, eu aproveito aquela oportunidade" (P17). Entretanto, "se eu tiver o dinheiro pra pagar por qualidade, eu prefiro" (P8).

Por meio de uma pesquisa relacionada ao consumo de bens de conveniência, Motta e Rossi (2003) detectaram que a necessidade de preservar o meio ambiente ainda não é um fator relevante na decisão de consumo; e, mesmo quando há a possibilidade de escolha, a importância é revertida para as vantagens que a utilização do produto pode proporcionar. Ou seja, que aquele produto "supra a minha necessidade e que ele possa ter uma

revista brasileira educação ambiental 
durabilidade ou qualidade no nível do que eu espero" (P6). As conclusões de uma pesquisa realizada com jovens pelo Instituto Akatu (2009) também apontaram que os critérios adotados nas compras estão relacionados mais aos pontos básicos de marketing de produto, como preço e qualidade, do que às consequências sociais e ambientais que esses produtos possam vir a causar. Segundo a mesma pesquisa, os jovens brasileiros ainda não estão preparados para o consumo responsável e sentem falta de mais informações sobre as questões ambientais.

No caso desse estudo, a compra, o consumo e o descarte referem-se às questões relacionadas ao preço e ao consumismo enfatizados pelos respondentes. Pelas análises das falas, percebe-se que há a declaração de que o consumismo existe, mas não há nenhuma intenção declarada de que este possa ser questionado, diminuído ou controlado. O que é mais importante ao fazer compras é a utilidade do produto, "se eu estou realmente precisando daquilo ali ou se estou só querendo consumir". O comportamento de consumir por impulso é questionado, não pela variável ambiental, mas porque tal atitude acabaria por causar problemas financeiros para o próprio indivíduo, uma vez que "a gente vê muitas promoções, às vezes a gente compra um produto que a gente não precisa só porque tá com um preço mais baixo, mas não é aquilo que é prioridade pra mim, não tô precisando daquilo ali no momento" (P5). Parte-se do pressuposto de que os professores, na sua maioria, demonstram saber que o ser humano e a industrialização são causadores da degradação ambiental, pois "(...) o que temos visto são intervenções que o homem tem feito [...] em busca de um avanço, mas que esse avanço, esse progresso tão desejado, tem resultado, tem transformado a nossa sociedade numa sociedade menos humana" (P1).

Apesar disso, poucos demonstram a intenção de promover ações de reparação dos danos que, assumidamente, causam. Com relação ao uso de energia elétrica que, em prol de um conforto, mesmo que aumente o custo, prefere-se desperdiçar, uma vez que "eu só sei dormir com a TV ligada, então virou um hábito (...) eu acho que disso aí eu tenho 'consciência' que tenho que melhorar" (P17). Essa consciência não é de fato uma consciência, mas apenas conhecimento de que a atitude está sendo prejudicial ao meio ambiente, mas que não gera nenhuma mudança de comportamento no sentido dessa variável ambiental. Varey (2010) argumenta que o consumismo, além de ser insustentável, não é considerado como tal, ou seja, as pessoas não identificam seu hiperconsumo como o causador dos problemas ambientais.

Lipovetsky (2007, p. 341) nos diz que "a hora é do controle ou da limitação do consumismo", já que a felicidade consumista, voltada para interesses imediatos, hoje é reconhecida como culpada por degradar a ecosfera. Portilho (2005) argumenta que os questionamentos sobre os padrões de consumo deveriam estar relacionados à forma 'como' e 'o quanto' usamos os recursos. O discurso de "se eu gostar e se eu puder comprar" (P11) não gera reflexões. Da mesma forma, o professor P12 afirma que "vai muito da 
necessidade [...] por exemplo, minha máquina de lavar quebrou, eu vou lá e compro outra".

Quando questionados acerca do que pode ser feito para contribuir com a conservação do meio ambiente, acreditam que a adoção de práticas "que são fáceis da gente fazer que é o controle do uso da água (...) utilizar produtos que podem ser utilizados mais vezes. Essas coisas mais básicas" (P9). Neste sentido, Connolly e Prothero (2003, p. 289) constataram que "o consumidor não relaciona seu consumo diário com a degradação ambiental" e concluem que os consumidores não identificam o atual nível de consumo como um problema e, sim, acreditam que uma das contribuições é "dentro da sua própria casa, você começar a selecionar o lixo, né. Você fazer a sua seleção (...) na minha casa, a gente seleciona, a gente separa, né. Aí tem uma senhora lá no Aeroporto, que a gente leva pra ela, o orgânico e o inorgânico", mas mesmo essa seleção deve envolver facilidades, uma vez que "a gente só faz jogar por cima da casa dela" (P1).

Ao comprar produtos, por exemplo, alimentícios, o consumidor está preocupado com aspectos da sua própria saúde, ou seja, "quando se trata de produtos alimentícios, olho a questão do teor de sódio, se tem gordura trans" (P14). Em outras palavras, a professora P16 afirma que "se é alimento eu vejo direto a validade e o que compõe aquele produto. Mas, às vezes, eu não me preocupo tanto em como ele está embalado, que aquilo ali vai gerar um lixo. Eu me preocupo com o conteúdo que eu vou consumir". Em síntese, aspectos relacionados à compra de produtos alimentícios, ou mesmo a preocupações relacionadas à alimentação, foram mais evidentes nos professores da área da Enfermagem. A aproximação com preocupações ambientais foram predominantes nos professores da área da Agropecuária. Acredita-se que por conta da própria formação, percebe-se que o discurso esteja impregnado com aspectos da profissão ou do conteúdo curricular dos cursos nos quais atuam.

Com relação à variável (b) Limitação do professor enquanto consumidor, diversos fatores indicaram obstáculos ao comportamento próambiental, sendo que a falta de informação ou a falta de tempo são indícios que limitam a falta de ação. "Nós não temos esse hábito, infelizmente [...] eu não sei se por conta da falta de conhecimento do assunto, que realmente não é um assunto fácil. Eu não sei se também por conta da correria do dia a dia, você acaba misturando tudo e se esquece, não presta atenção" (P1).

Roberts (1996) também cita algumas razões para o comportamento não tão consciente do consumidor, entre elas: que os produtos verdes são "muito caros, que não chegam com facilidade à nossa mesa" (P1); "a qualidade do produto extremamente associada ao preço" (P9); e que faltam informações.

Quanto às informações disponíveis aos consumidores acerca do processo de produção das empresas, "o problema é a gente saber" (P15); "essa informação é muito pouco divulgada" (P17); "a gente não tem tanto acesso a essa informação" (P6); "acho que a maioria das pessoas não procura isso" (P5); "eu nunca prestei atenção nesse aspecto" (P7); "não tive essa

revista brasileira educação ambiental 
preocupação ainda. Ainda não parei pra analisar isso" (P12). "Se alertados fôssemos, que aquela empresa tá danificando, a gente mudaria até mesmo como uma forma de protestar. Mas o difícil de fazer isso é porque no dia a dia a gente não sabe" (P16). Motta e Rossi (2003) verificaram que consumidoras de bens de conveniência, na faixa etária entre 25 e 48 anos, não são afetadas em seu processo de decisão de compra pelo fato de o produto ser ou não ambientalmente correto e que isso é ocasionado, basicamente, pela falta de informação.

Aspectos econômicos são enfatizados, pois mesmo quando se afirma que "eu nunca vi um produto que polua o meio ambiente. Se eu soubesse, não sei se evitaria, depende do preço" (P9). "Provavelmente eu já comprei e ela [empresa] polui. Isso aí não vai fazer eu deixar de comprar se eu precisar do produto" (P8). Holliday, Schmidheiny e Watts (2002) enfatizam que os consumidores precisam de informações sobre os produtos, de forma a tomar decisões inteligentes. A maioria das empresas, para o professor P18, "não está preocupada com essa questão ambiental e sustentabilidade. Eu acho que a maioria, principalmente no Brasil, está preocupada com altas margens de lucro". E complementa afirmando que "se você parar de consumir produtos que estão afetando o meio ambiente [...] Vai ter muito pouco produto para você consumir por que a maioria [das empresas] não está preocupada com a questão do meio ambiente".

Percebe-se que há certo receio em consumir produto reciclado, "não tenho essa prática [...] porque hoje em dia ele é bem mais caro" (P17). Layrargues (2000) complementa ao enfatizar que os consumidores compram produtos ambientalmente corretos (verdes), desde que estes não sejam dispendiosos e nem tenham qualidade inferior. Assim, as evidências indicam que os critérios influenciadores da decisão de compra dos professores enquanto consumidores estão voltados mais às questões de preço e qualidade e, algumas vezes, à validade dos produtos e ao status, do que propriamente à preocupação com um consumo responsável. Em outras palavras, a variável ambiental não aparece como um fator de decisão de compra. Neste contexto, cabe salientar que os professores dizem saber que "a questão da coleta de lixo, essa aí acho que pra gente que vive em área urbana" (P17) é importante. "Como a gente aumentou esse negócio de comprar pronto, come e descarta (...) se tu vê o tanto de lixo. E um lixo que não é utilizado, porque tem muito papel". Mas admitem que "se a gente tivesse o hábito de dividir o lixo pra ser [re]utilizado, bem, mas nós não temos" (P9) e que esta atividade não faz parte dos seus comportamentos diários; "geralmente não tem separação, só quando tem alguma coisa especial, a gente bota na pracinha [local onde tem um posto de coleta]" (P13); "é tudo junto. A gente ainda só separa vidro pra evitar do pessoal se cortar na hora de pegar" (P9).

Muitas falas demonstraram que ações em prol do meio ambiente não são atitudes inerentes aos professores e que, contraditoriamente, em alguns casos, se autodenominam ambientalmente conscientes e responsáveis "sim, eu tento pelo menos jogar o lixo" (P13). A preocupação com o destino final do 
lixo gerado não apareceu em nenhuma fala de modo espontâneo, o que destoa o discurso verde das práticas diárias esperadas, ao menos por aqueles que se autodenominam conscientes. O gerenciamento dos resíduos aparece como "terceirizado". Em outras palavras, "se tiver uma coisa de separação de lixo, eu pratico. Na minha casa eu não faço porque não existe coleta aqui na minha cidade de lixo individualizado, separado por coisa e por conta disso eu não tenho esse costume" (P17). Ou seja, a necessidade de uma ação que seja primeiramente externa.

De forma geral, embora muitas pessoas demonstrem estar dispostas a orientar suas compras segundo princípios ambientais, na vida real, não se demonstram dispostas a abrir mão dos produtos e padrões de preço e desempenho aos quais estão acostumadas (HOLLIDAY; SCHMIDHEINY; WATTS, 2002). Estes conflitos são aprofundados na próxima variável e podem ser explicados pelo fato de o consumidor se sentir impotente em suas ações cotidianas no sentido de não assumir seu poder de consumidor para dirimir os impactos ambientais.

A variável (c) Impotência do professor enquanto consumidor está relacionada à contradição presente entre a intenção e a prática de ações ambientalmente corretas no que tange ao fato de o consumidor ter a crença de que suas ações individuais não impactam negativamente e nem têm tamanha influência na degradação global. Indivíduos impotentes pretendem se engajar, mas se consideram muito "pequenos" e acreditam que não têm o poder de influenciar as mudanças necessárias, pelo fato de que "não está tanto, assim, em nossas mãos, a gente não tem como controlar muito isso (...) isso aí deve ter uma política pública muito extensa, e a gente, eu acho que é muito pequeno. Então devia ter uma conscientização muito grande" (P2).

A percepção entre os professores é de que suas ações ainda são pouco significativas ou mesmo inexistentes em relação ao meio ambiente. "Eu também fico muito incomodada quando eu vejo uma sala de aula aberta, com o ar condicionado ligado e as lâmpadas também. E todo mundo passando e ninguém faz nada. [...] são pequenas coisas que a gente vai se indignando com o passar do tempo sem poder resolver" (P4). Conforme a Teoria do ValorNorma-Crença de Stern e Dietz (1994), comportamentos pró-ambientais ocorreriam com maior probabilidade caso os indivíduos acreditassem que poderiam contribuir com a redução das ameaças ambientais.

O surgimento de sentimentos como incômodo ou indignação ao ver outras pessoas agindo de forma irresponsável com relação ao meio ambiente ou mesmo o sentimento de "raiva quando eu vejo alguém desperdiçando água" (P6) está fortemente correlacionado com o compromisso e com o comportamento de conservar a natureza (KALS; SCHUMACHER; MONTADA, 1999). A professora P9 relata que "[...] tem um problema ambiental que me inquieta muito, que é a eutrofização do (rio) Poti, aquelas águas, aquelas plantas aquáticas, aquilo ali me deixa meio desesperada quando eu vejo o rio quase fechando". No mesmo sentido, a professora P10 relata que "quando eu passo pela ponte da primavera que eu vejo o rio Poti naquele estado muito

revista brasileira educação ambiental 
degradado e nossas autoridades, infelizmente, não estão nem ai. A gente olha para aquela agua e vê nitidamente uma nuvem de poluição [...]".

Dessa forma, pressupõe-se que ao verificar relatos como "eu fico incomodada", "a gente vai se indignando", "eu morro de raiva", os participantes, naturalmente, adotariam em suas práticas diários comportamentos ambientalmente responsáveis. Entretanto, ter um comportamento ecológico não significa que todas as ações do indivíduo serão ecológicas, pelo fato desse tipo de comportamento apresentar vários antecedentes (DE YOUNG, 2000; SCHULTZ, 2000; STERN, DIETZ, 1994).

"Uma coisa é saber, a outra coisa é imprimir isso aí no seu ritmo de vida, é duas coisas completamente diferentes. Que eu me preocupo, me preocupo, observo. Faz alguma coisa pra mudar? Não. Faz a sua parte? Não" (P9). Neste ponto, infere-se que os professores enquanto consumidores impotentes agem sem comprometimento, pois acreditam que, por meio de suas ações individuais, não têm o poder de interferir de forma positiva para evitar a degradação ambiental.

Demonstram também que não têm a intenção de abdicar da satisfação de seus interesses pessoais. "Por exemplo, aquela questão de tomar banho e desligar o chuveiro na hora que tá se ensaboando, eu não faço, se eu não escutar a zuadinha do chuveiro, é que nem tomar banho e não lavar o cabelo. Eu morro se não molhar a cabeça" (P17). Percebe-se que existe uma pressão interna referente ao que poderia ser feito, mas esta intenção nem sempre se reflete na ação comportamental.

Varey (2010, p. 115) propõe questionamentos relacionados à visão moderna de aceitação do pensamento antropocêntrico: "Quem é culpado? Consumidores exigem as coisas boas para sua vida e produtores são gratos por isto, pois artificialmente eles estimulam o consumo para manter produção", mas "quem arca com o custo do desperdício dos resíduos, da degradação do meio ambiente, da obsolescência e do espetáculo que a promoção de estilos de vida baseados em marcas promove?".

Para conservar o ambiente, os valores e atitudes das pessoas necessitam mudar (STERN, 2000). Há, portanto, a necessidade de serem promovidos padrões sustentáveis relacionados às crenças, valores e atitudes para que os comportamentos sejam reflexos de um maior comprometimento com o futuro e preservação da própria espécie, pois os recursos naturais estão sendo consumidos em ritmo muito mais acelerado do que a capacidade de regeneração destes recursos. Estes fatores serão explorados na próxima subseção, que trata da racionalidade ecológica, ou seja, o direcionamento do pensamento para a ecologia e não só para fatores econômicos.

A categoria Racionalidade ecológica está dividida em duas variáveis: (a) Intenção pró-ambiental; e (b) Comportamento pró-ambiental. A intenção representa a vontade de agir de forma ambientalmente correta e o comportamento relaciona-se à ação propriamente dita. Esta distinção nas práticas de consumo relatadas foi necessária, pois, embora, muitas vezes,

Revbea, São Paulo, V. 11, № 1: 108-129, 2016. 
exista uma intenção declarada, constatou-se que esta não se traduz em ações efetivas. Intenções nem sempre resultam em um comportamento real (SOLOMON, 2011). Os consumidores podem manifestar a intenção de consumir de forma mais consciente, mas, muitas vezes, essa verbalização não condiz com atitudes reais.

Existe uma pressão interna declarada pelos próprios entrevistados de que "poderia" haver uma postura mais ativa, já vez que sabem o que seria necessário fazer, mas estas ações acabam não acontecendo, ou seja, "não vou atrás disso" (P2), "eu me preocupo muito, mas acho que ainda falta internalizar" (P13).

Cabe ressaltar que, quando questionados acerca de suas práticas de consumo diário, ou seja, às ações pró-ambientais efetivas, estas não foram mencionadas com a mesma ênfase como foram declaradas as intenções. Por estarem mescladas nos relatos, as variáveis das práticas de consumo referentes à Intenção e ao Comportamento são apresentadas em conjunto, de forma a fazer a contraposição necessária entre a intenção e o consequente comportamento manifestado (ou não).

Segundo Abdul-Muhmin (2007), a intenção representa um plano para agir de forma responsável, mas é uma variável dependente de muitos outros fatores e pressupõe a existência de condições facilitadoras destas ações ambientalmente corretas, como: alternativas de produtos ecológicos e existência de unidades de reciclagem. Neste sentido, a racionalidade ecológica relacionada à intenção foi percebida de maneira bastante controversa. Estas citações corroboram os resultados de outros estudos que demonstram haver uma discrepância entre a intenção de agir em prol do meio ambiente e a ação, já que as evidências indicam que a intenção não se traduz em comportamentos pessoais ambientalmente corretos (CASTRO, 2003; STERN, 2000), uma vez que "consciente eu sou. Eu tenho consciência de que o que eu faço não está correto, eu não tenho é a prática. Não tenho todos os cuidados que deveria ter" (P9). Muitos estudos têm obtido uma baixa correlação entre a intenção da pessoa em relação a algo e seu real comportamento (SOLOMON, 2011).

Constata-se que há uma tendência a pensar conforme o esperado para uma sociedade sustentável, ou seja, de forma ambientalmente responsável, mas esta intenção ainda não se traduz nos comportamentos cotidianos. Quando questionados a respeito de se considerarem consumidores ambientalmente conscientes ou não, observamos que alguns admitiram que "sim, eu tento pelo menos jogar o lixo, né, no lixo, né. A questão, a gente tenta" (P13).

A maior parte dos entrevistados declarou que "ambientalmente consciente, ainda não. Eu acho que ainda falta muito" (P1), "porque eu acho que a minha vida, o meu jeito de levar a minha vida não tem um impacto positivo pra parte de conservação ambiental. Eu tenho uma pequena consciência, mas como a vida da gente é muito corrida, eu não tenho muito o que botar em prática" (P17).

revista brasileira educação ambiental 
Quando questionados acerca das práticas de consumo, "eu não vou dizer que eu sou uma pessoa que pensa demais no ambiente, mas assim eu me preocupo muito, mas acho que ainda falta internalizar a importância dessa economia, em relação, pensando em nível de futuro do meio ambiente" (P13). Há uma visão de que o consumo tem que ser reduzido em prol de ter que economizar financeiramente. Nota-se que a variável ambiental aparece distante, algo que não requer uma mudança no comportamento.

$O$ reconhecimento de que o progresso sem precedentes provoca desequilíbrios na natureza (EGRI; PINFIELD, 2010) e que as atividades humanas estão alterando os ecossistemas dos quais a existência humana - $\mathrm{e}$ a de todos os seres vivos - é dependente (DUNLAP et al., 2000; NORDLUND; GARVILL, 2002), aliado à conscientização crescente sobre a necessidade de alcançar formas mais sustentáveis de desenvolvimento, levam a uma reavaliação e maior preocupação relacionada à forma como todos estão se relacionando com o ambiente. Existe, contudo, outra grande diferença entre o discurso e a prática. Para Portilho (2005), o simples acesso a conhecimentos relacionados à questão ambiental não leva a estilos de vida e práticas ambientalmente corretas. Conhecer as causas dos problemas pode conduzir a ações pró-ambientais, mas nem todos os professores entrevistados agem realmente neste sentido. Percebe-se que a contribuição individual acontece "adotando as práticas de preservação ambiental que são fáceis da gente fazer, que é o controle do uso da água" (P9), por exemplo.

Os comportamentos declarados como pró-ambientais refletem-se em atos isolados de alguns respondentes, como, por exemplo, "selecionar o lixo. Na minha casa eu seleciono, a gente separa" (P1), "a economia da água" (P2) e da "energia. Não deixar a casa toda acesa" (P9) ou mesmo "até com relação também aos descartáveis, também eu não utilizo muito" (P5). Estas pequenas atitudes são importantes, mas não tenderão a alterar os impactos negativos e a degradação ambiental global, sendo necessária, para isso, uma mudança de comportamento mais profunda. $O$ fato de ser consciente ambientalmente está relacionado a estar consciente em si mesmo, pensando no próprio "bolso", "porque se eu tô com minha casa toda iluminada, ligo o ar condicionado, o ventilador, o consumo vai aumentar no final do mês, a energia, então isso pesa, não só a consciência ambiental, mas também no bolso" (P5).

A falta de comprometimento nas ações cotidianas, "consumo de água, energia elétrica, esse tipo de atitude, eu sou um pouco é, assim, eu não sou muito econômico nisso não" é assumida por alguns professores, embora outros não tenham coragem de declarar "disso aí eu tenho consciência que tenho que melhorar" (P17). Constata-se que os professores não mencionaram nenhum comportamento relacionado a reduzir o próprio consumo. Existem preocupações e parece haver intenção, "falta agir mais porque embora você tenha consciência, mas muitas vezes você não age" (P1); "qual é o gargalo? É o fazer. Não adianta só ter essa consciência e não praticar" (P11), o que indica não saber ao certo a importância de operacionalizar, de forma a transformar 
estas vontades em comportamentos. Essa operacionalização no exercício da profissão é percebida na tentativa de repassar o que sabe para os alunos.

Constata-se, assim, que os professores não pretendem abdicar do que Ihes é conveniente e também não associam a geração dos dejetos produzidos diariamente nas suas residências como sendo parte das causas da degradação ambiental. Resumidamente, quando as perguntas relacionadas à preocupação foram confrontadas com as intenções de um lado e os comportamentos de outro, os resultados apontam para duas considerações: (1) o que os respondentes intencionam fazer, não é o que fazem; e (2) existe mais preocupação do que ação.

Os professores reconhecem que sua contribuição poderia fazer a diferença, mas mantém a posição passiva ao declarar que "como a vida da gente é muito corrida, eu não tenho muito o que botar em prática" (P17). A falta de compromisso é justificada por ser "uma coisa que a gente tá criando aos pouquinhos, é devagar, que ninguém tem esse hábito" ou mesmo "por conta da falta de conhecimento do assunto, que não é realmente um assunto fácil" (P1). Em algumas situações, a responsabilidade para com o meio ambiente é repassada às futuras gerações, ou seja, "a minha filha mais nova foi quem colocou, está nos ensinando" (P1). Em outras palavras, eles mesmos se consideram em uma posição ainda passiva e esperam respostas positivas de seus filhos em relação ao meio ambiente.

O imperativo categórico ético proposto por Jonas (2006, p.86) é que "os efeitos da tua ação sejam compatíveis com a permanência de uma autêntica vida humana sobre a terra". Para o filósofo, o homem é o único ser que pode ter responsabilidade, isso significa que a responsabilidade é cuidado reconhecido como dever - cuidado que, ante a ameaça da vulnerabilidade, se converte em preocupação. Nesse estudo, há, de um lado, os comportamentos ambientalmente conscientes (esperados), que são ligados à nova proposta de uma racionalidade mais ecológica e, de outro lado, os comportamentos declarados, que, na verdade, demonstram a racionalidade econômica vigente.

Percebe-se que as preocupações ambientais, por exemplo, "a água vai ser um problema ambiental grande também, a falta de água (...) eu acho que intervém diretamente na condição de sobrevivência da espécie humana na Terra", são transformadas em ação pelo viés da economia, de uma preocupação consigo mesmo, uma vez que "o que eu mais contribuo é com a economia da água (...) se eu vejo uma torneira aberta, eu desligo; ao escovar dentes, eu desligo; não ficar lavando carro, tomando banho de maneira exagerada, essas coisas" (P2).

Embora o conhecimento sobre o que é consumir de modo ambientalmente consciente esteja presente, é aparente o descaso e a falta de comprometimento individual. Para corroborar estas dicotomias, os relatos do Quadro 2 apresentam algumas contradições percebidas entre a intenção e a ação. 
Quadro 2: Contradições entre intenção e ação.

\begin{tabular}{|c|c|c|}
\hline Professor & Intenção & Ação \\
\hline P1 & $\begin{array}{l}\text { Ao comprar o produto você } \\
\text { observar, que tipo de produto } \\
\text { que você tá comprando, se } \\
\text { aquele produto, se ele danificou } \\
\text { ou não o meio ambiente. }\end{array}$ & $\begin{array}{l}\text { Eu acho que falta mais é prática mesmo, sabe, } \\
\text { desse lado ambiental. Eu acho que falta agir mais } \\
\text { porque embora você tenha consciência, mas } \\
\text { muitas vezes você não age }[\ldots]\end{array}$ \\
\hline P5 & $\begin{array}{l}\text { [...] usar de forma consciente } \\
\text { aquilo que a natureza nos } \\
\text { proporciona. }\end{array}$ & $\begin{array}{l}{[\ldots] \text { às vezes a gente compra um produto que a }} \\
\text { gente não precisa só porque tá com um preço } \\
\text { mais baixo }[\ldots]\end{array}$ \\
\hline P6 & $\begin{array}{l}\text { Me preocupo de tentar também, } \\
\text { contribuir para não poluir [...] }\end{array}$ & $\begin{array}{l}\text { [...] quando existe assim promoção, esse tipo de } \\
\text { situação [...]talvez me leve a um consumo mais } \\
\text { acelerado ou talvez aumentando. }\end{array}$ \\
\hline P8 & $\begin{array}{l}\text { Reduzir a produção de lixo } \\
\text { diária, que é muita. }\end{array}$ & $\begin{array}{l}\text { Não tenho programa de reciclagem. (...) Se } \\
\text { houvesse uma coleta seletiva, eu separaria. }\end{array}$ \\
\hline P9 & $\begin{array}{l}{[\ldots] \text { utilizar produtos que podem }} \\
\text { ser utilizados mais vezes. }\end{array}$ & $\begin{array}{l}\text { Como a gente aumentou esse negócio de } \\
\text { comprar pronto [...] E aí leva a poluição [...] se a } \\
\text { gente tivesse o hábito de dividir o lixo pra ser } \\
\text { utilizado, bem, mas nós não temos. }\end{array}$ \\
\hline P17 & $\begin{array}{lrrr}\text { Eu acho } & \text { que } & \text { a } & \text { minha } \\
\text { contribuição } & \text { é } & \text { tendo } \\
\text { consciência. } & & & \end{array}$ & $\begin{array}{l}\text { [...] tomar banho e desligar o chuveiro na hora } \\
\text { que tá se ensaboando, eu não faço }[. . .] \text { também } \\
\text { não sou muito econômico, eu só sei dormir com a } \\
\text { TV ligada. }\end{array}$ \\
\hline
\end{tabular}

Fonte: Autoria própria.

Em suma, identifica-se que os valores declarados pelos entrevistados nesta pesquisa resumem-se, na realidade, a uma orientação de valores relacionada ao egoísmo, que conduz a comportamentos para satisfação de interesses pessoais. Para Varey (2010), há um conflito perene na sociedade atual entre atingir interesses individuais e coletivos. As tendências observadas nos discursos analisados demonstram que os consumidores estão na contramão da história, pois contrariam a possibilidade de atingir o ideal de sociedade globalizada e sustentável.

As intenções pró-ambientais aparecem, algumas vezes, enquanto educador, "como sou enfermeira, a questão da educação e saúde, né, é uma ferramenta de trabalho que a gente pode utilizar com a população (...) tentar trazer a importância de não poluir, de não queimar, de economizar a água" (P13). A capacidade de responsabilidade é uma capacidade ética, tendo como mola propulsora a "aptidão ontológica do homem de escolher entre alternativas de ação com saber e vontade" (JONAS, 2006, p.88).

A importância da figura do professor enquanto profissional educador fica clara quando se aborda sobre em que medida pode se estar contribuindo para conservar o meio ambiente. "[...] posso contribuir pra cultivar nos alunos uma consciência de preservação ambiental [...] eu vejo que, muitos deles, por estarem em formação, eles não têm aquela consciência. Aí eu posso agir nesse sentido" (P6). Percebe-se que aliar a atividade profissional à consciência 
ambiental pode ser um caminho para as pessoas fazerem algo em favor do meio-ambiente. Inclusive quando se parte da premissa que se educa através do exemplo, seja para os filhos, seja para os alunos. "[...] a gente contribui desde o momento de formação dos nossos filhos até aqui na formação dos nossos alunos. Acho que isso é muito importante, a gente ter essa consciência para repassar e para falar. A experiência e o exemplo são tudo" (P10).

Como responsabilidade é um correlato do poder, o "deves, portanto podes" de Kant necessita ser substituído por "podes, portanto deves" (JONAS, 2006, p.212-330). Pelo visto, a nova dimensão da responsabilidade concerne ao que se tem de fazer, ao que ainda não é ao dever do poder. Trata-se da obrigação de responder pelo que está compreendido no âmbito de poder de uma pessoa ou instituição. Corresponde ao futuro da natureza e da humanidade. Observa-se que se operou a passagem do plano individual para 0 coletivo. Alguns professores reconhecem seu papel na sociedade e admitem que "como professora, eu acho que aí sim seria minha grande contribuição (...) mostrar pra eles [alunos] que temos como produzir utilizando técnicas agroecológicas, técnicas que preservem o meio ambiente" (P9). Nesse sentido, Jonas (2006) apresenta e propõe a ética do agora e do futuro. É preciso cuidar responsavelmente dos bens que é de toda a humanidade e ela é responsável por cuidar e procurar meios para que outros possam apreciar e ter os mesmos cuidados. É preciso, portanto, agir responsavelmente para com o patrimônio da humanidade.

Portilho (2005) defende uma análise das práticas de consumo a partir de uma redefinição daquilo que é tradicionalmente visto como o terreno da cidadania, da política e das relações de poder a serem transformadas, o que exige uma ampliação e um aprofundamento da concepção de cidadania que inclua o conjunto de práticas sociais e culturais. Nessa perspectiva, as ações e escolhas cotidianas são percebidas como sendo capaz de influenciar rumos globais. Desse modo, o sujeito social ao incorporar às práticas de consumo valores como a ética e a responsabilidade, assumem uma postura de politização da ambientalização, significando uma nova cultura de participação política, "tudo é uma questão de cultura" (P1), o que caracteriza a cidadania do consumidor, capaz de promover transformações socioambientais.

Evidencia-se que as práticas de consumo necessitam incorporar, valores e compromissos éticos, pois o indivíduo através da abordagem da ética da responsabilidade é capaz de restringir a capacidade humana de agir como destruidor da autoafirmação do ser na existência da vida e da natureza para, a partir de então, promover um desenvolvimento sustentável. Por isso, a ética da responsabilidade tem uma dimensão pedagógica que se desloca em todas as direções do agir humano. Nesse sentido, faz-se necessário repensar uma nova ética nas práticas de consumo, que deverá ser pautada em princípios que levem em consideração uma relação do homem com a natureza mais afetiva, pois só é possível promover mudança ética se houver um relacionamento afetivo com a natureza (JONAS, 2006). "Em termos de humanidade, em termos de solidariedade, porque no momento que eu me preocupo com o meio

revista brasileira educação ambiental 
ambiente, isso significa que eu me preocupo com o outro" (P1). Portanto, este cenário, aponta para a necessidade de um consumo sustentável, na medida em que as questões contemporâneas envolvem problemas tão complexos como a sustentabilidade do planeta, a solidariedade social, os direitos humanos e do consumidor enquanto direitos de cidadania.

Dessa forma, as práticas de consumo referenciadas pela ética da responsabilidade socioambiental apontam para o que seria um interesse público e coletivo, estas práticas convocam o consumidor individualmente a adotar novos comportamentos como prática de cidadania. Portilho (2005) assinala que existe a possibilidade de transformações sociais a partir da soma de atitudes individuais. Sendo assim, a incorporação de valores como a ética e a responsabilidade nas práticas de consumo para o enfrentamento dos problemas socioambientais tendo como aporte teórico-metodológico a ética da responsabilidade de Jonas (2006), com proposta de uma ética na relação homem-natureza, pode significar a ambientalização da politização. Portanto, o caminho da exequibilidade da ética e da responsabilidade, necessita ser trilhado por uma linha capaz de integrar e articular o discurso e a ação nas diversas dimensões para segmentar analiticamente a realidade, procurando construir a síntese da interação dinâmica.

\section{Conclusões}

A análise das falas dos professores possibilitou ter uma fotografia das suas práticas de consumo. Estes apontaram para uma relação paradoxal entre tentativas de conservar o meio ambiente, mas também atingir interesses pessoais, com aspectos bem marcantes da racionalidade econômica dominante. Os professores privilegiam muito mais o preço e a qualidade e a marca em detrimento da variável 'meio ambiente' nas suas decisões cotidianas de compra, consumo e descarte. Assim, infere-se que a conscientização e a preocupação ambiental ainda se apresentam incipientes, com tendências a não culminar em mudanças comportamentais de compra e consumo.

Não há a percepção individual da urgência de mudar os próprios comportamentos, mas, sim, ainda a falta de disposição em abrir mão de certas comodidades adquiridas na modernidade. O professor enquanto consumidor sente-se pequeno, impotente. Comportamentos ambientalmente significantes, como: fazer coleta seletiva, buscar diminuir o consumo, prestar mais atenção ao que compram e como descartam não foram atitudes habituais relatadas.

A questão relacionada ao consumo sustentável está longe de ser resolvida. Estamos diante de novos dilemas e desafios, em que se faz necessário amplos debates envolvendo diferentes segmentos sociais através de uma articulação mutuamente benéfica para todos. Neste sentido, recomenda-se a ampliação deste estudo, através da realização de pesquisas que avaliem qualitativamente e quantitativamente as ações que estão sendo implementadas pelos diversos atores sociais e institucionais para sanar os danos já causados ao meio ambiente, bem como estudos que possibilitem o 
desenvolvimento de mecanismos de consumo sustentável entre os diversos atores sociais envolvidos na temática que possam garantir o futuro através do desenvolvimento sustentável. Em última análise, este ensaio deve servir para alertar contra as prescrições simplistas para a mudança que se almeja alcançar em relação aos padrões e níveis de consumo atuais.

Uma proposta para mudar esse cenário estaria relacionada à formação docente, que contemplasse aspectos de sensibilização e uma aproximação com o meio ambiente. A realização de uma proposta de educação ambiental envolve processos de construção e reconstrução de saberes entrecruzados. Não basta professar uma opção teórica, é necessário perceber a materialização dessa opção em termos de organização. Dessa forma, o Colégio poderia (re)organizar o currículo a partir da educação ambiental anunciando, assim, essa opção em suas rotinas e vivências cotidianas, em suas formas de organização e desenvolvimento das práticas pedagógicas, de sua proposta curricular, enfim, precisa demonstrar-se a partir de seu fazer cotidiano. A partir daí, os projetos de articulação intercurricular, articulado com as diversas áreas e envolvendo os diferentes cursos técnicos, seriam exemplos de como articular os pressupostos teóricos e indicativos metodológicos da educação ambiental.

\section{REFERÊNCIAS}

ABDUL-MUHMIN, A. G. Explaining consumers' willingness to be environmentally friendly. International Journal of Consumer Studies, v. 31, p. 237-247, 2007.

BARBOSA, L. Sociedade de consumo. 3. ed. Rio de Janeiro: Zahar, 2010.

BARDIN, L. Análise de conteúdo. Lisboa: Edição 70, 2009.

BECK, C. G. Consumo ambientalmente consciente: os meus, os seus e os nossos interesses. 2010. 223f. Dissertação (Mestrado em Administração) Programa de Pós-Graduação em Administração, Universidade Federal da Paraíba, João Pessoa, 2010.

BLACKWELL, R.; MINIARD, P.; ENGEL, J. Comportamento do consumidor. São Paulo: Pioneira Thomson Learning, 2005.

BOFF, L. Saber cuidar: ética do humano - compaixão pela Terra. 19 ed. Petrópolis: Vozes, 2013.

CAMPBELL, C. Eu compro. Logo, sei que existo: as bases metafísicas do consumo moderno. In: BARBOSA, L.; CAMPBELL, C. (Org). Cultura, Consumo e Identidade. Rio de Janeiro: Editora FGV, 2006.

CASTRO, P. Pensar a natureza e o ambiente: alguns contributos a partir da Teoria das Representações Sociais. Estudos de Psicologia, Campinas, v. 8, n. 2, p. 263-271, 2003. 
CESCHIM, G.; MARCHETTI, R.Z. O comportamento inovador entre consumidores de produtos orgânicos: uma abordagem qualitativa. Anais do XXXIII EnANPAD. São Paulo: ANPAD, 2009.

CONNOLLY, J.; PROTHERO, A. Sustainable consumption: Consumption, consumers and the commodity discourse. Consumption, Markets and Culture, v. 6, n. 4, p. 275-291, 2003.

COSTA, D.V.; TEODÓSIO, A.S.S. Desenvolvimento sustentável, consumo e cidadania: Um estudo sobre a (Des)Articulação da comunicação de organizações da sociedade civil, do Estado e das empresas. Revista de Administração Mackenzie, São Paulo, v. 12, n. 3, p. 114-145, 2011.

DUNLAP, R.E. et al. Measuring endorsement of the New Ecological Paradigm: A revised NEP scale. Journal of Social Issues, v. 56, n. 3, p. 425-442, 2000.

EGRI, C.P.; PINFIELD, L.T. As organizações e a biosfera: ecologia e meio ambiente. In: CLEGG, S.T.; NORD, W.R.; HARDY, C. (Org.). Handbook de Estudos Organizacionais. Tradução de: Handbook of Organizational Studies, v. 1, cap. 14. São Paulo: Atlas, 2010.

FEATHERSTONE, M. Cultura de Consumo e Pós-modernismo. Tradução de: Consumer Culture and Postmodernism. São Paulo: Studio Nobel, 1995.

GIL, A.C. Como elaborar projetos de pesquisa. São Paulo: Atlas, 1996.

HOLLIDAY, Jr. C.O.; SCHMIDHEINY, S.; WATTS, P. Cumprindo o Prometido: Casos de Sucesso de Desenvolvimento Sustentável. Rio de Janeiro: Campus, 2002.

INSTITUTO AKATU. Estilos Sustentáveis de Vida - Resultados de uma pesquisa com jovens brasileiros - 2009. São Paulo: Instituto Akatu, 2009. Disponível em: http://www.akatu.org.br/Content/Akatu/Arquivos/file/Publicacoes/EstilosSustent aveisdeVida.pdf . Acesso em: 24 jun. 2014.

JONAS, H. O Princípio Responsabilidade: ensaio de uma ética para uma civilização tecnológica. Rio de Janeiro: PUC Rio, 2006.

KNAPP, D. The Thessaloniki Declaration: A wake-up call for environmental education? The Journal of Environmental Education, v. 31, n. 3, p. 32-39, 2000.

LAYRARGUES, P.P. Sistemas de gerenciamento ambiental, tecnologia limpa e consumidor verde: a Delicada relação empresa-meio ambiente no ecocapitalismo. Revista de Administração de Empresas, São Paulo, v. 40, n. 2, p. 80-88, abr./jun., 2000.

LIPOVETSKY, G. A Felicidade Paradoxal: Ensaio sobre a Sociedade do Hiperconsumo. São Paulo: Companhia das Letras, 2007.

MINAYO, M.C.S. (Org.) Pesquisa social: teoria, método e criatividade. 22. ed., Rio de Janeiro, Vozes, 2003. 
MOTTA, S.L.S.; ROSSI, G.B. A influência do fator ecológico na decisão de compra de bens de conveniência: um estudo exploratório na cidade de São Paulo. RAE - Revista de Administração de Empresas, São Paulo, v. 38, p. 46-57, 2003.

NORDLUND, A.M.; GARVILL, J. Value structures behind proenvironmental behavior. Environment and Behavior, v. 34, p. 740-756, 2002.

PEIXOTO, A.F.; PEREIRA, R.C.F. Discurso versus ação no comportamento ambientalmente responsável. Revista de Gestão Ambiental e Sustentabilidade - GeAS, São Paulo, v.2, n.2, p. 71-103, 2013.

PORTILHO, F. Consumo sustentável: limites e possibilidades de ambientalização e politização das práticas de consumo. Cadernos EBAPE. BR, Edição Temática, p. 1-12, 2005.

PORTILHO, F. Consumidores de alimentos orgânicos: discursos, práticas e auto-atribuição de responsabilidade socioambiental. Anais da XXVI Reunião Brasileira de Antropologia. Porto Seguro, 2008.

PORTILHO, F. Sustentabilidade Ambiental, Consumo e Cidadania. 2. ed., São Paulo: Cortez Editora, 2010.

ROBERTS, J.A. Green consumers in the 1990's: profile and implications for advertising. Journal of Business Research, v. 36, p. 217-231, 1996.

SCHULTZ, P.W. The structure of environmental concern: Concern for self, other people, and the biosphere. Journal of Environmental Psychology, v. 21, p. 327-339, 2001.

SOLOMON, M.R. O comportamento do consumidor: comprando, possuindo e sendo. 9. ed. Porto Alegre: Bookman, 2011.

STERN P. C. Toward a coherent theory of environmentally significant behavior. Journal of Social Issues, v. 56, n. 3, p. 407-424, 2000.

STERN, P.C.; DIETZ, T. The value basis of environmental concern. Journal of Social Issues, v. 50, n. 3, p. 65-84, 1994.

STOLLE, D.; HOOGHE, M.; MICHELETTI, M. Politics in the supermarket: political consumerism as a form of political participation. International Political Science Review,.v. 26, n. 3, p. 245-269, 2005.

THOMPSON, S.C.G.; BARTON, M.A. Ecocentric and anthropocentric atitudes toward the environment. Journal of Environmental Psychology, v. 14, p. 149158, 1994.

VAREY, R.J. Marketing means and ends for a sustainable society: a welfare agenda for transformative change. Journal of Macromarketing, v. 30, n. 2, p. 112-126, 2010.

WARDE, A. Consumption, Taste and Social Change. In: Consumption, Food and Taste: culinary antinomies and commodity culture. London: SAGE Publications, p. 7-42, 1997.

revista brasileira educação ambiental 